\title{
Deletion of the Candida albicans histidine kinase gene CHK1 improves recognition by phagocytes through an increased exposure of cell wall $\beta$-1,3-glucans
}

\author{
Nina Klippel, Shuna Cui, Lothar Groebe and Ursula Bilitewski \\ Helmholtz Centre for Infection Research, Inhoffenstrasse 7, 38124 Braunschweig, Germany
}

Correspondence

Ursula Bilitewski

ursula.bilitewski@helmholtz-hzi.de

Received 25 March 2010

Revised 12 July 2010

Accepted 2 August 2010

\begin{abstract}
The pathogenic fungus Candida albicans is able to cover its most potent proinflammatory cell wall molecules, the $\beta$-glucans, underneath a dense mannan layer, so that the pathogen becomes partly invisible for immune cells such as phagocytes. As the C. albicans histidine kinases Chk1p, Cos $1 p$ and CaSln $1 p$ had been reported to be involved in virulence and cell wall biosynthesis, we investigated whether deletion of the respective genes influences the activity of phagocytes against $C$. albicans. We found that among all histidine kinase genes, $C H K 1$ plays a prominent role in phagocyte activation. Uptake of the deletion mutant $\Delta c h k 1$ as well as the acidification of $\Delta c h k 1$-carrying phagosomes was significantly increased compared with the parental strain. These improved activities could be correlated with an enhanced accessibility of the mutant $\beta-1,3-$ glucans for immunolabelling. In addition, any inhibition of $\beta$-1,3-glucan-mediated phagocytosis resulted in a reduced uptake of $\Delta c h k 1$, while ingestion of the parental strain was hardly affected. Moreover, deletion of $C H K 1$ caused an enhanced release of interleukins 6 and 10, indicating a stronger activation of the $\beta-1,3$-glucan receptor dectin-1. In conclusion, the Chk1p protein is likely to be involved in masking $\beta$-1,3-glucans from immune recognition. As there are no homologues of fungal histidine kinases in mammals, Chk1p has to be considered as a promising target for new antifungal agents.
\end{abstract}

\section{INTRODUCTION}

The pathogenic yeast Candida albicans is a commensal organism, but can cause mycoses, particularly in immunocompromised individuals such as patients undergoing chemotherapy, or suffering from transplant immunosuppression or HIV infection. Diseases caused by $C$. albicans range from local, superficial infections of the skin and mucosa to life-threatening systemic candidiasis. $C$. albicans bloodstream infections have recently been described as resulting in mortality rates of more than $40 \%$ (Moran et al., 2009). Though antimycotic agents are available, treatment is complicated due to the host toxicity of the common antifungal agents, especially of amphotericin $\mathrm{B}$, and the emergence of drug-resistant C. albicans strains (Chauhan \& Calderone, 2008; Cowen \& Steinbach, 2008; Singh et al., 2009).

To establish a successful infection within the host, $C$. albicans expresses numerous virulence factors, including the morphological switch between yeast and hyphal growth, secretion of hydrolytic enzymes, biofilm formation, and the ability to adhere to host surfaces (Calderone

Abbreviations: HK, heat-killed; IL, interleukin; MAP kinase, mitogenactivated protein kinase; PMN, polymorphonuclear leukocyte; RFU, relative fluorescence units; TLR, Toll-like receptor.
\& Fonzi, 2001; Mitchell, 1998; Siqueira \& Sen, 2004; Stehr et al., 2000). Moreover, the structure of the C. albicans cell wall, in particular the arrangement of polysaccharides, i.e. $\beta$-glucans, mannans and chitin, influences the immune response and thus the pathogenicity of the fungus (Chaffin et al., 1998; Ruiz-Herrera et al., 2006). Particularly the $\beta$ glucan layer is of major relevance for host-pathogen interactions (Poulain \& Jouault, 2004). Phagocytes, like macrophages and neutrophils, which act as a first line of immune defence against fungal infections, express different transmembrane pattern recognition receptors (PRRs), of which several are activated by binding $\beta$-glucans, so that these cells are mainly stimulated by these immunomodulatory compounds (Herre et al., 2004; Taylor et al., 2002). One of the major $\beta$-glucan-recognizing PRRs is the C-type lectin-like receptor dectin-1 (Brown et al., 2002; Gow et al., 2007; Willment \& Brown, 2008). Once activated, dectin-1 triggers defence mechanisms such as uptake and killing of the pathogen as well as inflammatory processes. In addition, the Toll-like receptors (TLRs) and mannan receptors also interact with fungal cell wall constituents. These interactions stimulate cytokine production, but unlike dectin-1, these receptors are not known to trigger phagocytosis (Le Cabec et al., 2005; Lee et al., 2003; Netea et al., 2008). Thus, $\beta$-glucans are important for the immune defence against $C$. albicans, but the pathogen 
predominantly hides its $\beta$-glucan layer underneath a dense coat of mannoproteins and thereby avoids recognition of the $\beta$-glucans by the immune system (Netea et al., 2008; Ruiz-Herrera et al., 2006; Wheeler \& Fink, 2006).

Uncovering mechanisms responsible for the regulation of the cell wall structure, such as masking of $\beta$-glucans, could provide novel targets for anti-Candida agents. It is noteworthy that the two-component signal transduction systems of $C$. albicans are known to be related to the virulence and cell wall biosynthesis of this pathogenic fungus (Kruppa \& Calderone, 2006). In these cascades, signalling is achieved by a multistep transfer of a phosphoryl group from histidine to aspartate ('phosphorelay'), a principle that does not exist in mammalian cells, which generally use serine, threonine or tyrosine phosphorylation of proteins (Santos \& Shiozaki, 2001). Thus, two-component signal transduction systems have recently been discussed as promising antifungal drug targets (Chauhan \& Calderone, 2008). Histidine kinases are integral parts of these pathways. In C. albicans, three histidine kinases have been identified: CaSln $1 \mathrm{p}$, Cos1p (also known as CaNik1p) and Chk1p (Alex et al., 1998; Calera et al., 1998; Nagahashi et al., 1998). Deletion of any of the encoding genes causes an impaired pathogenicity of C. albicans in mouse systemic candidiasis models (YamadaOkabe et al., 1999), but the most dramatic effects have been described for CHK1-deficient strains (Calera et al., 1999). In the study of Torosantucci et al. (2002) on the interaction of $\Delta c h k 1$ and human neutrophils, enhanced killing of the mutant was observed, which was ascribed mainly to an increased sensitivity of the mutant to stress conditions within the phagocytic cell. However, the interaction was not investigated in more detail. Furthermore, disruption of CHK1 leads to an alteration in the structure of cell wall mannans and the amount of $\beta$-glucans (Kruppa et al., 2003). In that study, mannan chains, which normally shield the $\beta$-glucans from the environment, were truncated and the amount of $\beta$-glucans was reduced. Due to these findings, an exposure of the $\beta$-1,3-glucan layer of the mutant can be assumed, even though there is no direct experimental evidence so far. Even less is known about the influence of the other two histidine kinases, CaSln1p and Coslp, on cell wall biosynthesis, although a comparison of the expression of genes involved in mannan synthesis in mutants lacking one of the histidine kinase genes has indicated that each of the $C$. albicans histidine kinases regulates similar functions in cell wall assembly (Kruppa et al., 2004).

Signalling from histidine kinases is considered to be transmitted through a phospho-histidine intermediate protein to a response regulator, of which $C$. albicans possesses two, CaSsk1p and CaSkn7p (Calera \& Calderone, 1999b; Singh et al., 2004). Unlike histidine kinases, CaSkn7p is not required to establish a successful infection within the host (Singh et al., 2004). CaSsk1p is essential for the pathogenesis of $C$. albicans, since disruption of the encoding gene causes the total loss of virulence in a mouse model of haematogenously disseminated candidiasis (Calera et al., 2000). Furthermore, CaSsk1p regulates a subset of genes whose functions are associated with cell wall biosynthesis and stress adaptation (Chauhan et al., 2003). The relationship between CaSsk1p and the three histidine kinases is poorly understood. There is evidence that a CaSln1p-CaSsk1p cascade regulates activation of the mitogen-activated protein (MAP) kinase CaHog1p (high osmolarity glycerol) (Bahn, 2008; Kruppa \& Calderone, 2006). CaHoglp is mainly responsible for mediating osmotic stress resistance by triggering expression of glycerol synthesis-related genes, but participates in the regulation of cell wall biosynthesis as well (Monge et al., 2006). However, a connection between CaSsk1p and the signalling pathways of the two other histidine kinases, Coslp and Chk1p, has also been discussed (Bahn et al., 2007; Kruppa \& Calderone, 2006; Santos \& Shiozaki, 2001).

In our study, the function of histidine kinases for the recognition of $C$. albicans by phagocytes, and thus for the escape from the immune system, was investigated. We present data indicating for what we believe to be the first time that deletion of Chklp leads to an enhanced internalization of the mutant, which can be traced back to an increased accessibility of $\beta$-glucans for antibody binding, so that it can be concluded that Chklp participates in processes of masking $\beta$-glucans from immune recognition. An involvement of the other histidine kinases as well as the response regulator CaSsk1p in these processes was found to be unlikely.

\section{METHODS}

Cultivation of macrophage cell lines. The murine macrophage cell lines RAW264.7 [American Type Culture Collection (ATCC) no. TIB-61] and J-774A.1 [German Collection of Microorganisms and Cell Cultures (Deutsche Sammlung von Mikroorganismen und Zellkulturen; DSMZ) no. Acc170] were routinely cultivated in Dulbecco's modified Eagle's medium (DMEM; Lonza) supplemented with $10 \%(\mathrm{v} / \mathrm{v})$ fetal calf serum (FCS; heat-inactivated for $30 \mathrm{~min}$ at $55{ }^{\circ} \mathrm{C}$, Lonza) and penicillin/streptomycin solution $\left(10 \mathrm{ml} \mathrm{l}^{-1}\right.$, Sigma) at $37{ }^{\circ} \mathrm{C}$ in a $10 \% \mathrm{CO}_{2}$ in air atmosphere. Cells were subjected to no more than 15 passages.

Preparation of murine and human polymorphonuclear leukocytes (PMNs). Murine PMNs were obtained from Priyanka Narang and Matthias Gunzer (formerly of the Helmholtz Centre for Infection Research, Braunschweig, Germany) and isolated as previously described (Behnsen et al., 2007). Briefly, mouse bone marrow cells were prepared by flushing the femurs and tibiae of BALB/c mice with PBS $+1 \%(v / v)$ FCS. Following erythrocyte lysis, cells were incubated with Fc Block (BD Pharmingen) and subjected to cell sorting by Gr-1labelled magnetic particles (clone RB6-8C5, BD Biosciences) according to the manufacturer's instructions.

Human PMNs were separated from whole blood of healthy donors by using the Polymorphprep kit system from Axis-Shield. Following the kit protocol, $5 \mathrm{ml}$ freshly drawn and anticoagulated blood (SMonovette with potassium EDTA, Sarstedt) was layered onto $5 \mathrm{ml}$ Polymorphprep solution and centrifuged at $500 \mathrm{~g}$ for $30 \mathrm{~min}$. Subsequently, the PMN fraction was harvested, diluted by the addition of $0.45 \% \mathrm{NaCl}$ solution, washed by centrifugation $(400 \mathrm{~g}$, 
$10 \mathrm{~min}$ ), and resuspended in RPMI medium (Lonza) supplemented with $10 \%$ FCS.

Cultivation and preparation of yeast strains. C. albicans strains used in this study are listed in Table 1. Saccharomyces cerevisiae BY4741 was obtained from EUROSCARF (Johann Wolfgang GoetheUniversity, Frankfurt am Main, Germany) (Brachmann et al., 1998). Yeasts were routinely cultivated in yeast extract peptone dextrose (YPD) medium (Sigma) at $30{ }^{\circ} \mathrm{C}$ with orbital shaking at 160 r.p.m. For infections, yeasts grown to stationary phase were harvested, and a concentration of $1 \times 10^{8}$ yeast cells $\mathrm{ml}^{-1}$ was obtained by dilution with PBS. Where necessary, yeast cells were heat-killed (HK) by heating to $65{ }^{\circ} \mathrm{C}$ for $1.5 \mathrm{~h}$. Following centrifugation $(16000 \mathrm{~g}, 5 \mathrm{~min}$, $24{ }^{\circ} \mathrm{C}$ ), yeasts were washed twice with $1 \mathrm{ml}$ PBS before the desired yeast concentration was adjusted in DMEM $+10 \%$ (v/v) FCS (heatinactivated for $30 \mathrm{~min}$ at $55{ }^{\circ} \mathrm{C}$, Lonza). This medium was used to maintain the maximum viability of the phagocytic cells, which was significantly affected in medium without serum when incubation times exceeded $1 \mathrm{~h}$. However, we heat-inactivated the serum, a treatment which is considered to inactivate the complement system so that the yeast cells are not opsonized.

For $\beta$-1,3-glucan digestion of the yeast cell wall, $1 \times 10^{8}$ yeasts were treated with $1 \mathrm{mg} \beta$-1,3-D-glucanase from Helix pomatia (Sigma) in $1 \mathrm{ml}$ sodium acetate buffer $(150 \mathrm{mM}, \mathrm{pH} 5.0)$ at $37^{\circ} \mathrm{C}$ overnight, and then yeast cells were washed twice with $1 \mathrm{ml}$ PBS before the desired yeast concentration was adjusted in DMEM $+10 \%$ FCS.

For phagocytosis or phagosome acidification assays, $1 \times 10^{8}$ yeast cells $\mathrm{ml}^{-1}$ were labelled with FITC (Sigma, $1.25 \mathrm{mM}$ in $0.1 \mathrm{mM}$ sodium bicarbonate buffer, $\mathrm{pH} 9.0,+0.5 \%$ DMSO) or Texas Red (Molecular Probes/Invitrogen, $0.06 \mathrm{mM}$ in $0.1 \mathrm{mM}$ sodium bicarbonate buffer, $\mathrm{pH} 8.3,+0.5 \%$ DMSO), respectively. After incubation at $4{ }^{\circ} \mathrm{C}$ overnight, yeasts were washed three times with PBS to remove unbound dye before the desired yeast concentration was obtained in DMEM $+10 \%$ FCS.

Phagocytosis assay. Phagocytosis of yeasts by RAW264.7 cells and PMNs was quantified as previously described (Klippel \& Bilitewski, 2007). Briefly, phagocytes were seeded in 96 -well plates $\left(2 \times 10^{6}\right.$ cells $\mathrm{ml}^{-1}, 100 \mu \mathrm{l}$ per well) and incubated for $2 \mathrm{~h}$ to let the cells adhere before the supernatant was replaced by $100 \mu$ l of a suspension of $4 \times 10^{6} \mathrm{ml}^{-1}$ FITC-labelled yeasts (see above) in DMEM supplemented with $10 \%$ FBS (host: pathogen ratio of $1: 2$ ). Phagocytosis was allowed to proceed at $37{ }^{\circ} \mathrm{C}$ in a $10 \% \mathrm{CO}_{2}$ in air atmosphere for up to $60 \mathrm{~min}$. At indicated time points, the yeast suspension was removed and trypan blue (Fluka, $250 \mu \mathrm{g} \mathrm{ml}^{-1}$ in PBS) was added to quench the fluorescence of the yeasts which were bound but not internalized by the phagocytes. After incubation at room temperature for $1 \mathrm{~min}$, the remaining fluorescence of the phagocytosed yeasts was determined through the bottom of the microtitre plate by a fluorimetric multi-well plate reader (CytoFluor Series 4000, PerSeptive Biosystems). Data analysis was based on the mean of the fluorescence values (relative fluorescence units; RFU) of at least eight wells per experiment. Background fluorescence was determined from the fluorescence of wells containing yeasts but no macrophages. Data are presented as total fluorescence minus background fluorescence.

For competitive inhibition of phagocytosis triggered by $\beta$-1,3-glucans, the supernatant of adherent RAW264.7 cells $\left(2 \times 10^{6}\right.$ cells ml ${ }^{-1}$, $100 \mu \mathrm{l}$ per well) was aspirated and $100 \mu \mathrm{l}$ laminarin per well (Sigma, $2 \mathrm{mg} \mathrm{ml}^{-1}$ in DMEM $+10 \%$ FBS), a $\beta$-1,3-glucan from the alga Laminaria digitata, was added followed by incubation for $10 \mathrm{~min}$ on ice to let the inhibitor bind to $\beta$-1,3-glucan recognition receptors without being ingested. Subsequently, unbound laminarin was removed and macrophages were infected with FITC-labelled yeasts, as described above.

Phagosome acidification assay. RAW264.7 cells $\left(1 \times 10^{5}\right.$ cells $\mathrm{ml}^{-1}, 750 \mu \mathrm{l}$ ) were seeded onto circular coverslips (Menzel, $20 \times 26 \mathrm{~mm}$ ) in four-well plates and allowed to adhere at $37{ }^{\circ} \mathrm{C}$ in a $10 \% \mathrm{CO}_{2}$ in air atmosphere for $2 \mathrm{~h}$. The supernatant was aspirated and $750 \mu \mathrm{l}$ of a suspension consisting of DMEM supplemented with $10 \%$ FBS, LysoTracker Green DND-26 (Molecular Probes/Invitrogen, $150 \mathrm{nM}$ ) and $1 \times 10^{6} \mathrm{ml}^{-1}$ Texas Red-labelled yeasts (host : pathogen ratio $1: 10$ ) was added. After incubation for $1.5 \mathrm{~h}$, coverslips were transferred onto a slide and observed by fluorescence microscopy (Axioplan, Zeiss). Analysis was done using the corresponding AxioVision 3.1 software (Zeiss). Successful acidification of phagosomes containing Texas Red-labelled yeasts was indicated by the appearance of both LysoTracker Green DND-26 and Texas Red fluorescence within the phagosomes. Consequently, merging of images of the different fluorescence channels resulted in yellow fluorescence. For quantitative analysis, the percentage of acidic (yellow) phagosomes per image was determined by counting yellow and red phagosomes.

Immunofluorescence labelling and detection of $\boldsymbol{\beta}$-1,3-glucans
and mannans. For immunofluorescence labelling of $\beta$-glucan and
mannan, yeasts were incubated with specific AlexaFluor 488-
conjugated antibodies and FITC-concanavalin A, respectively,
according to procedures given by Jouault et al. (2006) and Tkacz
et al. (1971), and labelling was detected via fluorescence microscopy
and flow cytometry.

Yeast cells $\left(3 \times 10^{6}\right)$ were washed twice with $1 \mathrm{ml}$ PBS containing $2 \%$ FBS $\left(16000 \mathrm{~g}, 5 \mathrm{~min}, 24^{\circ} \mathrm{C}\right.$ ) before $200 \mu \mathrm{l}$ monoclonal mouse anti$\beta$-1,3-glucan IgG (Biosupplies Australia, $7 \mu \mathrm{g} \mathrm{ml}^{-1}$ in PBS $+2 \% \mathrm{FBS}$ ) was added and incubated at room temperature for $30 \mathrm{~min}$. After stringent washing to remove unbound primary antibody, yeasts were incubated with $200 \mu \mathrm{l}$ AlexaFluor 488-labelled goat anti-mouse IgG (Invitrogen, $200 \mu \mathrm{g} \mathrm{ml}^{-1}$ in PBS $+2 \% \mathrm{FBS}$ ). As a negative control, only the secondary antibody was added. After incubation at room temperature for $45 \mathrm{~min}$, yeasts were washed again and fixed with $0.4 \%$ paraformaldehyde in PBS.

Yeast from an overnight culture was adjusted to a final $\mathrm{OD}_{620}$ of 0.1 ( $\mu$ Quant microtitre plate reader, BioTek) in $0.18 \mathrm{ml}$. The cells were

Table 1. Genetic background of the C. albicans strains used in this study

\begin{tabular}{|c|c|c|c|}
\hline Strain & Synonym & Genotype & Reference \\
\hline CAF2-1 & & $\Delta$ ura3: : imm434/URA3 & Fonzi \& Irwin (1993) \\
\hline$\Delta \operatorname{chk} 1$ & $\mathrm{CHK} 21$ & 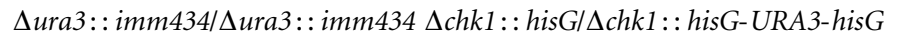 & Calera \& Calderone (1999a) \\
\hline$\Delta \operatorname{chk} 1 / C H K 1$ & CHK23 & 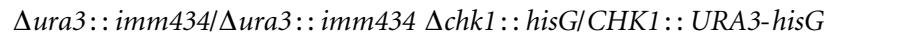 & Calera \& Calderone (1999a) \\
\hline$\Delta \cos 1$ & LAC17 & 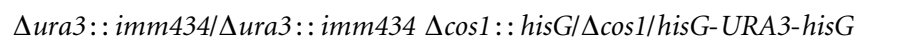 & Alex et al. (1998) \\
\hline$\Delta$ casln 1 & CaSLN1 & 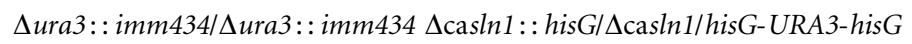 & Nagahashi et al. (1998) \\
\hline$\Delta$ cassk1 & SSK21 & 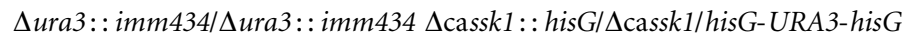 & Calera et al. (2000) \\
\hline
\end{tabular}


washed twice with $0.9 \% \mathrm{NaCl}$, collected by centrifugation and resuspended in $500 \mu \mathrm{l}$ of a FITC-concanavalin A solution (Sigma, stock solution $1 \mathrm{mg} \mathrm{ml}^{-1}$ ) diluted 1:50 with $0.9 \% \mathrm{NaCl}$. After $30 \mathrm{~min}$ at room temperature, cells were collected by centrifugation and washed twice with $1 \mathrm{ml} 0.9 \% \mathrm{NaCl}$. All reactions were performed at room temperature. After washing, cells were fixed in $0.4 \%$ formalin and analysed by flow cytometry.

Images of labelled yeasts were taken with a digital fluorescence microscope (Biozero BZ-8100E, Keyence) and processed using the corresponding software (BZ-8000 Image Analysis Application, Keyence). Fluorescence intensity was quantified on a BD FACSCanto flow cytometer (BD Biosciences). For data acquisition, forward and side scatter were detected on linear scales, while AlexaFluor 488 fluorescence was analysed on logarithmic scales. Yeast cells were gated by forward and side scatter based on the size and shape of intact yeasts, and the AlexaFluor 488 fluorescence intensity of at least 5000 gated cells was calculated using FACSDiva 5.0 software (BD Biosciences). The fluorescence histograms were performed in FlowJo 5.7.2 (Tree Star, Inc.)

Interleukin (IL) detection via ELISA. In a 96-well plate, adherent RAW264.7 macrophages $\left(5 \times 10^{5}\right.$ cells $\mathrm{ml}^{-1}, 100 \mu \mathrm{l}$ per well $)$ were infected with yeast cells $\left(1 \times 10^{5}\right.$ yeasts $\mathrm{ml}^{-1}$ in DMEM supplemented with $10 \% \mathrm{FBS}, 100 \mu \mathrm{l}$ per well) and co-incubated at $37{ }^{\circ} \mathrm{C}$ in a $10 \% \mathrm{CO}_{2}$ in air atmosphere for either $1 \mathrm{~h}$ (for IL-6 detection) or $6 \mathrm{~h}$ (for IL-10 detection). As negative controls, RAW264.7 cells were cultivated without yeasts. After centrifugation of the plates $\left(2250 \mathrm{~g}, 5 \mathrm{~min}, 4{ }^{\circ} \mathrm{C}\right)$, supernatants were collected and stored at $-80{ }^{\circ} \mathrm{C}$ until assays were performed. IL- 6 and IL- 10 concentrations were determined with ELISA kits (ELISA Ready-SET-Go!, eBioscience) according to the protocol of the manufacturer. For analysis, the difference with respect to the background of RAW264.7 cells cultivated without yeasts was considered.

Data analysis and statistics. Data analysis and the creation of diagrams were conducted with Microsoft Excel 2002 and OriginPro 8.1 (OriginLab Corp.), respectively. For comparative statistical analysis, Student's unpaired $t$ test was performed using Microsoft Excel 2002. $P$ values $<0.01$ were considered significant.

\section{RESULTS}

\section{Deletion of $\mathrm{CHK1}$ leads to a highly significant increase in phagocytosis of C. albicans}

The 3D arrangement of cell wall components of fungal pathogens is of major importance for the activation of immune defence reactions. As the three $C$. albicans histidine kinases CaSln $1 \mathrm{p}$, Coslp and Chk1p are known to participate in cell wall biosynthesis and virulence (Kruppa \& Calderone, 2006), we investigated the effects of the deletion of histidine kinase-encoding genes on the interaction between C. albicans and innate immune cells. Previously, we had established a quantitative fluorimetric phagocytosis assay (Klippel \& Bilitewski, 2007), which is performed in microtitre plates and in which fluorescence only from attached, and not from internalized cells, is quenched by trypan blue. Moreover, we used wells without phagocytic cells to control for quenching efficiency and occasionally controlled results by microscopic inspection. Thus, we could reliably detect internalized cells alone and perform time-course studies of the phagocytotic activity of the murine macrophage cell line RAW264.7 with the C. albicans histidine kinase mutants $\Delta c h k 1, \Delta c h k 1 / C H K 1$,
$\Delta \cos 1, \Delta \operatorname{cas} \ln 1$, the appropriate parental strain CAF2-1, and the non-pathogenic baker's yeast $S$. cerevisiae (Fig. 1a). Remarkably, phagocytosis of $\Delta c h k 1$ was significantly enhanced compared with that of CAF2-1. At all time points, fluorescence values representing the internalization of $\Delta c h k 1$ were at least fivefold higher than values of CAF2-1 (for all time points, $P<0.0001$ ). To verify that serum components had no influence, we repeated the experiments with CAF2-1 and $\Delta c h k 1$ without the addition of serum to the medium and obtained the same relative phagocytic efficiency (data not shown). Moreover, phagocytosis of $\Delta c h k 1$ was similar to that of $S$. cerevisiae, i.e. phagocytosis of the deletion mutant reached a non-pathogenic level. By contrast, uptake of the gene-reconstituted strain $\Delta c h k 1 / C H K 1$ and the other two histidine kinase mutants $\Delta \cos 1$ and $\Delta \operatorname{cas} \ln 1$ strongly resembled that of CAF2-1. These results indicated that among all C. albicans histidine kinases, Chk1p plays a prominent role in recognition and uptake of $C$. albicans by RAW264.7 cells. Due to these findings, further experiments were focused on the phagocytosis of $\Delta c h k 1$.

To validate the data obtained with RAW264.7 cells, we used J-774A.1 cells as an additional murine phagocyte cell line. As shown in Fig. 1(b), we found that like RAW264.7 cells, J774A.1 cells internalized $\Delta c h k 1$ more efficiently than CAF21 , especially during early time points $(30 \mathrm{~min})$. Next, we used freshly isolated murine PMNs (Fig. 1c) as well as human PMNs (Fig. 1d) in order to prove that primary phagocytes also exhibit an enhanced activity against $\mathrm{CHK1}$ deficient $C$. albicans yeasts. For both cell types, we indeed found an increased uptake of $\Delta c h k 1$ compared with CAF2-1. The difference seen in the phagocytotic activity of human and murine neutrophils, i.e. the higher activity of the human cells, is not significant, as it was strongly dependent on the human donor, and the time between isolation and application of the murine cells was longer than for the human cells, which may have decreased the activity. Thus, phagocytosis of different yeast strains by a given phagocyte can be compared, but not data from different primary phagocytes, and these results clearly demonstrated that deletion of $C H K 1$ yields a significantly enhanced phagocytosis of $C$. albicans yeasts by phagocytes from different sources. These data are not in full agreement with those obtained by Torosantucci et al. (2002), who did not observe an increased uptake rate in neutrophils. However, the phagocytosis activity in the earlier study was deduced from $\left[{ }^{3} \mathrm{H}\right]$ glucose incorporation into the respective yeast strain, which is a more indirect method to evaluate internalization and does not easily allow a distinction between attached and internalized yeast cells. Thus, the different results may be due to the different assay principles.

\section{Enhanced acidification of phagosomes containing $\Delta$ chk1}

Killing of internalized pathogens is attributed to the release of reactive oxygen and nitrogen species as well as to the fusion of phagosomes with lysosomes, which contain 

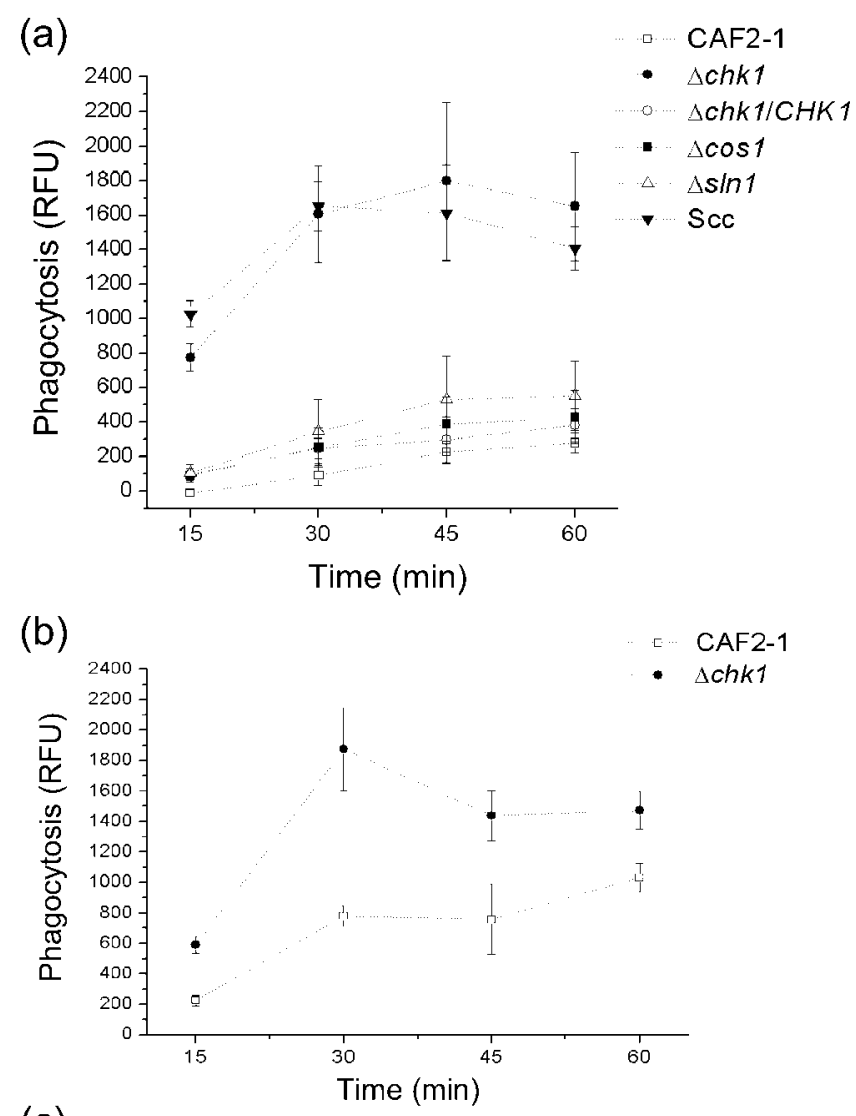

(c)

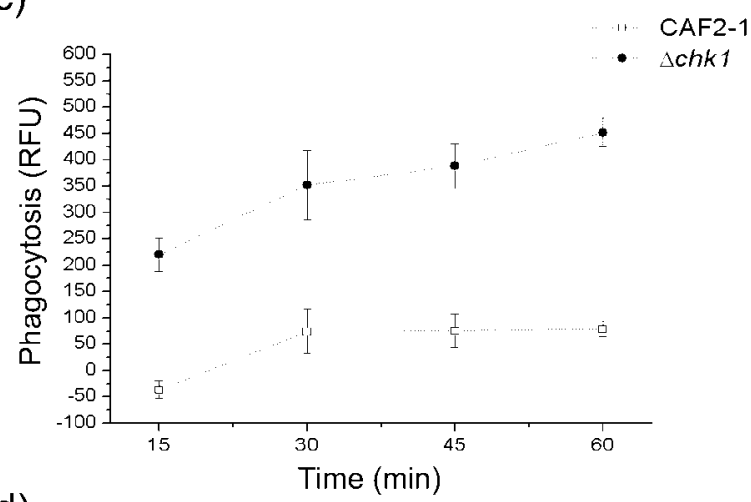

(d)

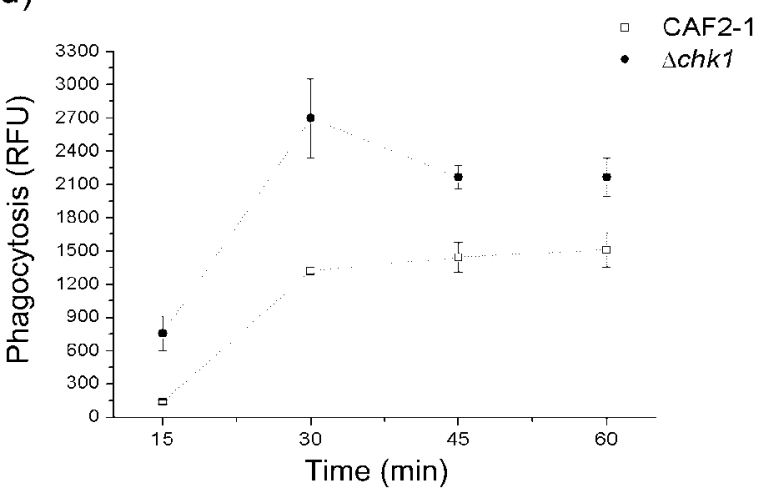

degradative enzymes in an acidic environment. Remarkably, C. albicans is able to escape being killed by phagocytes (Ibata-Ombetta et al., 2001). A study by Fernández-Arenas
Fig. 1. Deletion of $C H K 1$ strongly enhances phagocytosis of $C$. albicans. (a) Phagocytotic activity of RAW264.7 cells against the parental strain CAF2-1, the histidine kinase mutants $\Delta c h k 1$, $\Delta c h k 1 / C H K 1, \Delta \cos 1$ and $\Delta$ casln 1 , and S. cerevisiae (Scc). (bd) Phagocytotic activity of (b) J-774A.1 cells, and (c) murine and (d) human PMNs towards CAF2-1 compared with $\Delta$ chk1. Phagocytes were co-cultivated with FITC-labelled yeasts. At the indicated time points, phagocytosis efficiency was determined by measuring the fluorescence intensity from internalized yeasts. Fluorescence of attached but not ingested yeasts was quenched by adding trypan blue. Data shown are representative of at least three independent experiments. Error bars, SD.

et al. (2009) has recently provided evidence that living $C$. albicans actively modulates intracellular membrane trafficking in mouse macrophage phagosomes. It is conceivable that the histidine kinase Chk1p is involved in these defence reactions because it has been shown elsewhere that human PMNs have an enhanced growth-inhibitory and killing effect on a C. albicans strain that lacks CHK1 (Torosantucci et al., 2002). As histidine kinases of the pathogenic bacterium Ehrlichia chaffeensis are known to be involved in blocking the fusion of bacteria-containing phagosomes with lysosomes (Kumagai et al., 2006), we investigated whether deletion of CHK1 likewise affects the maturation of phagosomes carrying C. albicans yeast cells. As acidification is one of the major steps of phagosome maturation, we analysed the decrease of the phagosomal $\mathrm{pH}$ as representative of the overall process. Moreover, the study of Fernández-Arenas et al. (2009) had shown that the results obtained from acidification studies correlate well with those of other lysosome markers. Therefore, the null mutant $\Delta c h k 1$, the parental strain CAF2-1 and the non-pathogenic yeast $S$. cerevisiae were labelled with Texas Red and used for infection of RAW264.7 macrophages. Simultaneously, acidic organelles of the phagocytes were stained with the $\mathrm{pH}$ sensitive dye LysoTracker Green DND-26. Representative overlay images of the different fluorescence channels are shown in Fig. $2(\mathrm{a}-\mathrm{c})$. A green colour indicates the presence of an acidic organelle, i.e. the phagolysosomes, and red the presence of yeasts. If yeasts were found in acidic organelles, i.e. a green and a red colour were present in the same site, this resulted in yellow light and was taken as an indicator of successful phagosome maturation. In order to quantify the influence of the ingested yeast strains on phagosome acidification, we determined the proportion of acidic phagosomes of the total number of phagosomes by analysing a minimum of 200 phagosomes per strain (Fig. $2 \mathrm{~d})$. In fact, we found a highly significant difference between CAF2-1 and $\Delta \operatorname{chk} 1(P<0.0001)$. During infection with the mutant, $\sim 50 \%$ of the phagosomes showed an accumulation of the acid-specific fluorescent dye, whereas a mere $7 \%$ of the CAF2-1-containing phagosomes were found to be acidic. Moreover, the analysis of the images validated the results obtained from the fluorimetric phagocytosis assays (Fig. 1), because fewer internalized CAF2-1 compared with $\Delta$ chk1 


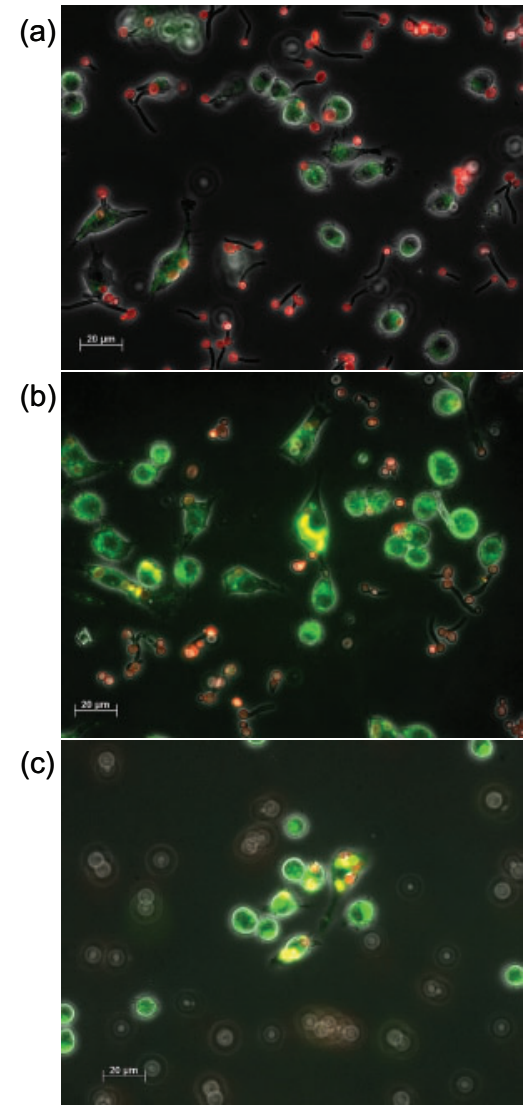

(d)

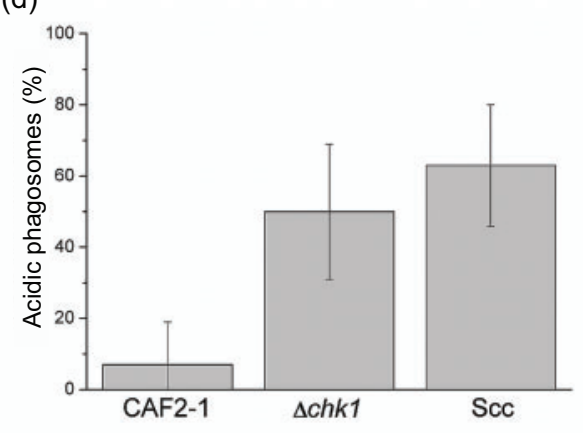

Fig. 2. Deletion of $C H K 1$ enhances the maturation of C. albicanscarrying phagosomes. RAW264.7 cells were loaded with the $\mathrm{pH}$ sensitive LysoTracker Green DND-26 and co-cultivated with living Texas Red-labelled (a) CAF2-1, (b) $\Delta$ chk1 and (c) S. cerevisiae yeasts for $1.5 \mathrm{~h}$. The representative microscopic overlay images display acidification of phagosomes. Yellow fluorescence results from accumulation of the acid-specific dye (green fluorescence) in phagosomes carrying yeasts (red fluorescence), and is considered an indicator of successful maturation. (d) The histogram quantitatively compares the percentage of acidified phagosomes with respect to the total number of phagosomes counted for each yeast strain (at least 200 phagosomes). Data are based on the mean of at least three independent experiments repeated on multiple days. Error bars, SD.

cells could be found. During infection with $S$. cerevisiae, $66 \%$ of the phagosomes became acidic, but the statistical evaluation revealed no significant difference between the
S. cerevisiae and $\Delta$ chk1 results $\left(\begin{array}{lll}P & \sim 0.2\end{array}\right)$. These data demonstrated that deletion of $C H K 1$ enhances acidification of phagosomes during infection with C. albicans to a level comparable with that of a non-pathogenic yeast.

\section{In $\Delta c h k 1$, the accessibility of $\beta-1,3-$ glucans is increased}

Earlier studies had shown that cell wall mannans of CHK1-deficient C. albicans yeasts are significantly truncated and that the glucan content is also lower than in the wild-type strain (Kruppa et al., 2003; Li et al., 2009). The inner $\beta$-glucan layer of the $C$. albicans cell wall is known to be shielded by these mannan chains (Netea et al., 2008; Wheeler \& Fink, 2006). However, it has been shown that treatment of C. albicans with subcritical concentrations of the antifungal compound caspofungin leads to both lower bulk levels and increased exposure of $\beta$-glucan (Wheeler \& Fink, 2006). Thus, we hypothesized that due to the shorter mannans the $\beta$-glucans of the mutant could be exposed to immune recognition. To verify this assumption, we compared the accessibility of $\beta$-1,3-glucans from $\Delta c h k 1$ and CAF2-1 for immunolabelling using an anti- $\beta$ 1,3-glucan antibody followed by an incubation with an AlexaFluor 488-labelled secondary antibody. In addition, HK CAF2-1 was included as a positive control because it has been shown that heat treatment of C. albicans leads to exposure of $\beta$-1,3-glucans (Jouault et al., 2006; MartínezEsparza et al., 2006). Immunolabelling of CAF2-1 resulted in only poor fluorescence (Fig. 3a), whereas $\Delta c h k 1$ was efficiently stained and achieved high median fluorescence intensities, indicating a high amount of accessible $\beta$-1,3glucans (Fig. 3b). In contrast to $\Delta c h k 1$, the revertant strain $\Delta c h k 1 / C H K 1$ showed low fluorescence values (data not shown), i.e. the reconstitution of the gene recovered the phenotype of the reference strain. High fluorescence intensities were obtained for HK CAF2-1 as well as $S$. cerevisiae (Fig. 3c, d), whereas the median fluorescence of antibody-stained $\Delta$ casln 1 and $\Delta \cos 1$ was only slightly increased compared with CAF2-1 (data not shown). These results clearly corroborated that among the histidine kinase genes, only the deletion of CHK1 leads to an increased $\beta$-1,3-glucan exposure on the C. albicans cell wall surface up to the levels of $S$. cerevisiae and HK CAF2-1.

As increased glucan accessibility could correlate with decreased amounts of accessible mannans, we studied the accessibility of mannans by staining with FITClabelled concanavalin A followed by FACS analysis. For all strains we observed significantly higher levels of mean fluorescence than for the glucan staining, which may be due to different affinities of the labelling reagents but also agrees with the presence of mannans as the outer layer. This higher basal level is probably the reason for the less pronounced effect of CHK1 deletion (as a percentage) on the reduction of mannan accessibility (Table 2). 
(a)

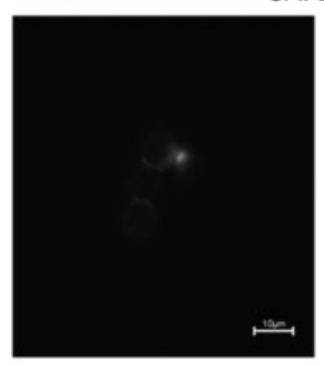

CAF2-1

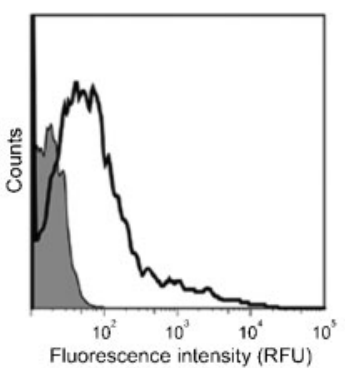

Fluorescence intensity (RFU)

(c)

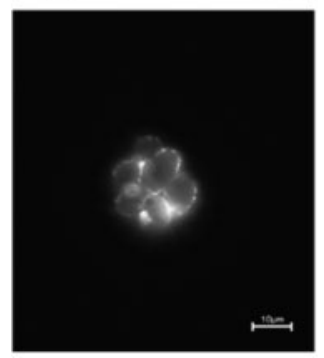

HK CAF2-1

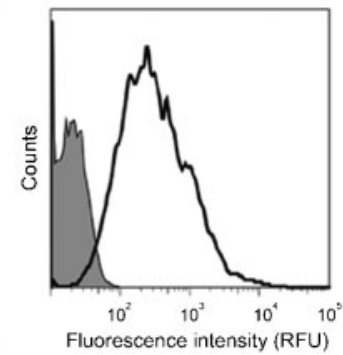

(b)

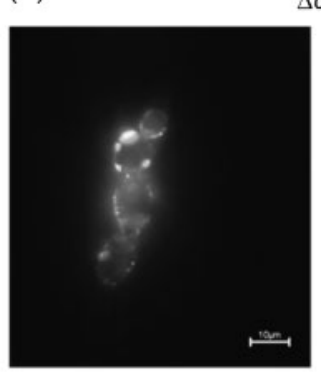

$\Delta \mathrm{chk1}$

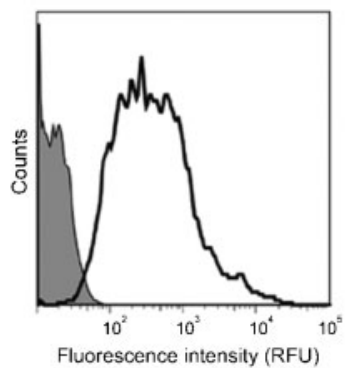

(d)

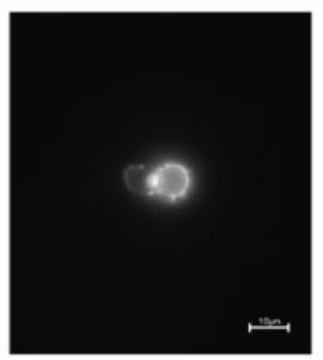

Scc

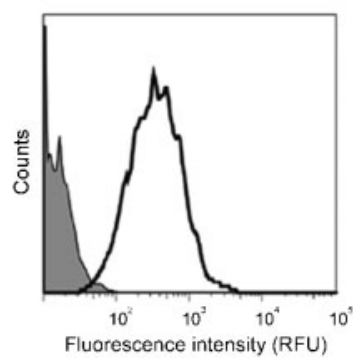

Fig. 3. Surface exposure of $\beta$-glucans of (a) CAF2-1, (b) $\Delta c h k 1$, (c) HK CAF2-1 and (d) S. cerevisiae (Scc). For flow cytometry, yeasts were probed with an anti- $\beta$-1,3-glucan antibody followed by incubation with an Alexa Fluor 488-labelled secondary antibody (open areas in histograms). Yeasts stained with the secondary antibody alone were taken as controls (shaded areas in histograms). For validation of the flow cytometric data, labelled yeasts were observed by fluorescence microscopy and representative microsopic images illustrate immunolabelling. Data show the results of three independent experiments. Bars, $10 \mu \mathrm{m}$.

\section{Phagocyte responses to HK CAF2-1 and $\Delta c h k 1$ are equivalent}

An early report had shown that phagocytosis of HK $C$. albicans by monocytes is mediated by $\beta$-glucan receptors (Janusz et al., 1988). Moreover, we previously observed that treatment of $C$. albicans with heat leads to an enhanced phagocytosis efficiency (Klippel \& Bilitewski, 2007). In addition, the study of Fernández-Arenas et al. (2009) has shown that living $C$. albicans cells are able to block phagosome acidification while HK cells are not. This could be due to the vitality of the pathogen, but also due to changes in cell wall structure, as $\beta$-glucans are also exposed in HK C. albicans. Due to these facts, we compared the activity of RAW264.7 macrophages towards HK CAF2-1 and $\Delta c h k 1$, and found that both yeast uptake and phagosome maturation during infection with HK CAF2-1 and $\Delta c h k 1$ reached equivalent levels (Fig. 4). By contrast, heat-killing of $\Delta$ chkl had almost no effect on these processes (data not shown). With regard to our finding that both deletion of $C H K 1$ and heat treatment of $C$. albicans lead to an enhanced $\beta$-1,3-glucan surface exposure (Fig. 3), the enhanced activity of macrophages towards HK CAF2-1 and $\Delta$ chkl can be attributed to an increased accessibility of the cell wall $\beta$-1,3-glucans for immune recognition.

\section{Perturbation of $\beta$-1,3-glucan interactions with phagocytes inhibits phagocytosis}

$\beta$-1,3-Glucan interactions with corresponding receptors of the macrophages were inhibited by either enzymic digestion of the yeast cell wall glucans using $\beta$-1,3glucanase or pre-incubation of the macrophages with laminarin $\left(2 \mathrm{mg} \mathrm{ml}^{-1}\right)$, a $\beta$-1,3-glucan from $L$. digitata which can compete with the yeast glucans for carbohydrate-binding receptors of the macrophages. As shown in Fig. 5(a), ingestion of $\Delta c h k 1$ pre-treated with $\beta-1,3-$ glucanase was significantly decreased, while uptake of CAF2-1 was only slightly affected by enzymic digestion. This effect was not due to an increased cell lysis resulting from $\beta$-1,3-glucanase treatment, as the viability of the yeast strains was not influenced (data not shown). However, it cannot be excluded that glucanase treatment leads to additional changes of the cell wall. That is why we complemented these investigations by those with the inhibitor laminarin. These data are shown in Fig. 5(b), and the effects of blocking $\beta$-1,3-glucan-dependent phagocytosis were similar to those of the enzymic digestion. Thus, we clearly demonstrated that $\beta$-1,3-glucans are strongly involved in the recognition and uptake of $\Delta c h k 1$ but not of CAF2-1 (under both inhibitory conditions, difference between mutant and CAF2-1: $P<0.001)$. The 
Table 2. Surface exposure of $\beta$-glucan and mannan of strains CAF2-1 and $\Delta$ chk1

\begin{tabular}{|lcrlll|}
\hline \multirow{2}{*}{ Strain } & \multicolumn{2}{c}{$\boldsymbol{\beta}$-Glucan exposure } & & \multicolumn{2}{c|}{$\begin{array}{c}\text { Mannan exposure } \\
\text { (RFU) }\end{array}$} \\
& \multicolumn{2}{c}{ Median } & & & \\
\cline { 2 - 3 } \cline { 5 - 6 } & SD & & Median & SD \\
\hline CAF2-1 & 182 & 84 & & 22942 & 4475 \\
$\Delta$ chk1 & 1006 & 180 & & 13855 & 1454 \\
\hline
\end{tabular}

role of $\beta$-1,3-glucans for phagocytotic uptake of $C$. albicans has been shown for caspofungin-treated yeast (Wheeler \& Fink, 2006) and recently for $\Delta c e k 1$ cells (Galán-Diez et al., 2010), but not yet for $\Delta c h k 1$ cells.

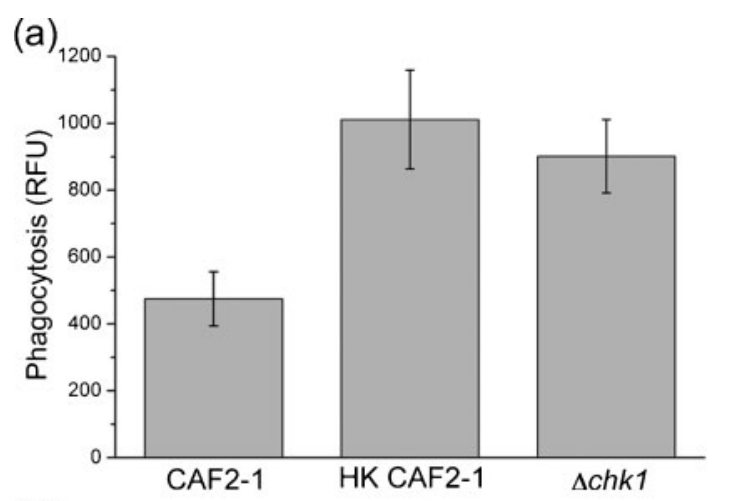

(b)

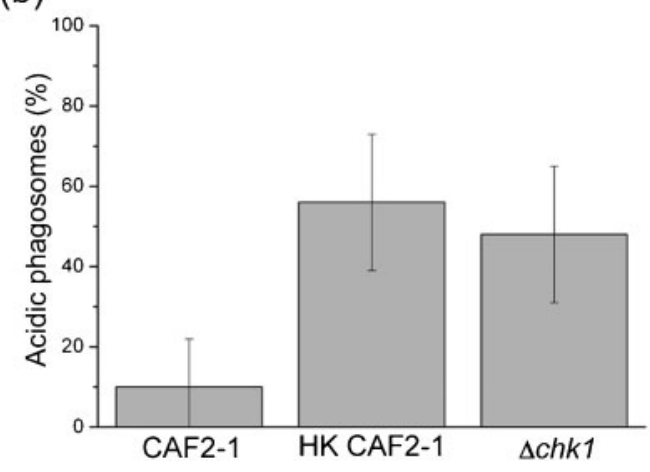

Fig. 4. Phagocyte responses to HK CAF2-1 in comparison with living CAF2-1 and $\Delta c h k 1$. (a) RAW264.7 cells were incubated with FITC-labelled yeasts for $45 \mathrm{~min}$. Fluorescence of nonphagocytosed yeasts was quenched via treatment with trypan blue before fluorescence of ingested yeast cells was measured. (b) A suspension of Texas Red-stained yeasts and LysoTracker Green DND-26 was added to RAW264.7 macrophages and incubated for $1.5 \mathrm{~h}$. Accumulation of the acid-specific dye in phagosomes containing Texas Red-stained yeasts was observed using fluorescence microscopy and the percentage of successfully acidified phagosomes was determined. At least 200 phagosomes were counted for each dataset. Respective histograms are based on the mean of three experiments performed on different days. Error bars, SD.

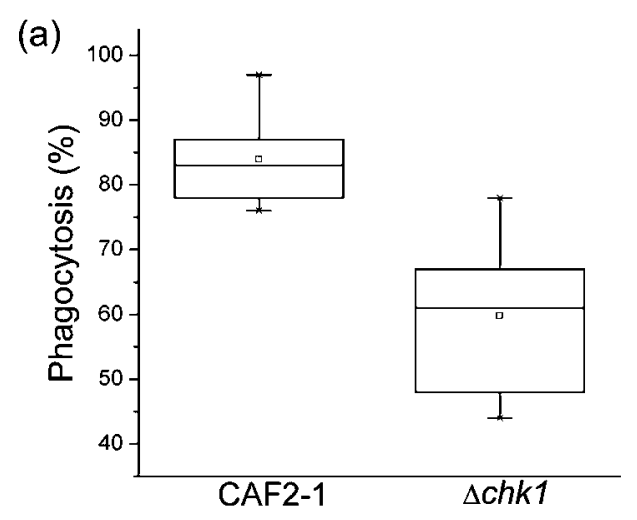

(b)

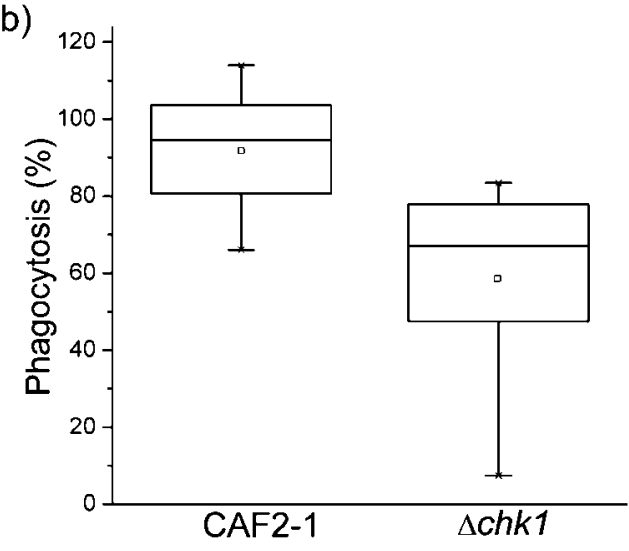

Fig. 5. Effects of the inhibition of $\beta$-glucan-mediated phagocytosis on the uptake of CAF2-1 and $\Delta$ chk1. (a) Yeasts were preincubated with $\beta$-glucanase or (b) RAW264.7 macrophages were pre-treated with the competitive inhibitor laminarin $\left(2 \mathrm{mg} \mathrm{ml}^{-1}\right)$ before the fluorimetric phagocytosis assay was performed (phagocytosis time $=45 \mathrm{~min}$ ). Boxplots show percentages of the residual phagocytosis with the values obtained from untreated cells set as $100 \%$. The bottom and top of the box represent the lower and upper quartiles. The band and the dot inside the box show the median and the mean of the data, respectively. Whiskers display minimum and maximum of all data. Analysis was based on at least 15 measurements. Experiments were repeated on multiple days.

\section{Deletion of CHK1 leads to an increased release of IL-6 and IL-10, which indicates an involvement of the $\beta$-1,3-glucan-specific phagocytosis receptor dectin-1 in recognition of $\Delta c h k 1$}

The major innate immune receptor for $\beta$-1,3-glucans is dectin-1 (Adams et al., 2008; Brown et al., 2002; Taylor et al., 2007), a C-type lectin-like receptor that triggers immune defence mechanisms such as phagocytosis, upregulation of immune killing mechanisms and the production of proinflammatory cytokines, and protects against fungal disease in mice (Gantner et al., 2005; Gow et al., 2007; Wheeler et al., 2008). Thus, the increased exposure of $\beta$-1,3-glucans on the surface of $\Delta$ chkl should enhance not only phagocytosis, which is stimulated via 
dectin-1, but also the secretion of cytokines, which are under the control of signal transduction pathways originating in ligand binding to dectin-1. Although the induction of proinflammatory cytokines includes collaborative signalling of dectin-1 with TLR2, in macrophages the activation of dectin-1 is sufficient for these effects (Steele et al., 2003). Among these cytokines are IL-6 and IL-10 (Gow et al., 2007; Meyer-Wentrup et al., 2007). Concentrations of IL- 6 and IL-10 were determined in the supernatants of RAW264.7 macrophages infected with $\Delta c h k 1$ and CAF2-1. In Fig. 6 it is shown that deletion of CHK1 indeed led to highly significant increases in both IL- 6 and IL-10 production $(P<0.001$ and $P<0.002$, respectively), indicating a stronger activation of dectin-1.

\section{CHK1-triggered signalling is not mediated through the response regulator CaSSK1}

Fungal histidine kinases are parts of two-component signal transduction systems in which phosphotransfer proceeds from histidine residues to aspartate residues in receiver domains of regulatory proteins (Chauhan \& Calderone, 2008; Kruppa \& Calderone, 2006). From these response regulators the signal is further transferred, for example to MAP kinase cascades. A well-known example is the pathway from the histidine kinase Casln1p to the MAP kinase $\mathrm{CaHog} 1 \mathrm{p}$ via the response regulator CaSsk1p. Recently, for Chk1p, a functional relationship with the MAP kinase Cek1p has been shown for some phenotypes, which also include mannan biosynthesis (Li et al., 2009). Moreover, it has been shown that Ceklp is also involved in $\beta$-1,3-glucan masking and correspondingly influences immune defence reactions (Galán-Diez et al., 2010). However, a pathway which links Chk1p directly to Ceklp

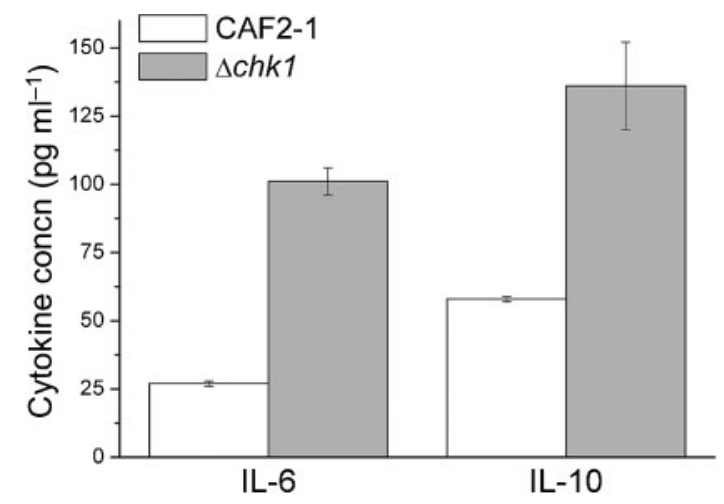

Fig. 6. Release of IL- 6 and IL-10 by RAW264.7 during infection with CAF2-1 and $\Delta c h k 1$. RAW264.7 cells were cultivated with yeasts for either $1 \mathrm{~h}$ (detection of IL-6) or $6 \mathrm{~h}$ (detection of IL-10). The IL concentration in the supernatant of each infection was determined via ELISA and the background of RAW264.7 cells cultured without yeasts was subtracted. Data show mean and SD of four replicates representing results of two independent experiments. and which comprises a response regulator downstream of Chklp has not yet been elucidated. In C. albicans, two response regulators are known, CaSsk1p and Skn7p (Calera \& Calderone, 1999b; Singh et al., 2004), but only CaSsk1p has been found to be involved in virulence and cell wall biosynthesis (Calera et al., 2000; Chauhan et al., 2003). However, it had not yet been shown whether CaSsk1p is integrated in the Chklp pathway. Thus, the interaction of the CaSSK1-deletion mutant $\Delta$ cassk1 (Table 1) with RAW264.7 macrophages was evaluated via phagocytosis efficiency and acidification of yeast-containing phagosomes, and compared with $\Delta c h k 1$ and CAF2-1 (Fig. 7). Although a slight increase in both uptake of $\Delta$ cassk1 (Fig. 7a) and phagosome maturation (Fig. 7b) was observed, statistical analysis revealed no significant difference from CAF2-1, whereas responses were significantly different from those of $\Delta$ chkl $(P<0.001)$. Thus, the deletion of CaSSK1 does not have the same effect on the activity of phagocytes as deletion of $C H K 1$, so that an interaction
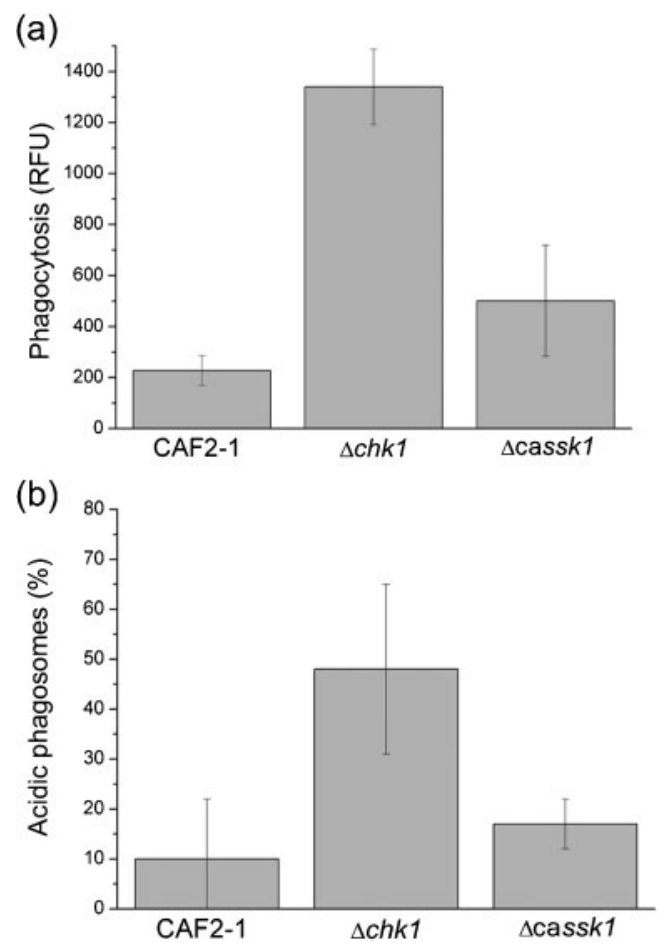

Fig. 7. Antifungal activity of RAW 264.7 towards $\Delta$ cassk 1 in comparison with $\Delta c h k 1$ and CAF2-1. (a) Phagocytosis efficiency of RAW264.7 cells for the different strains given as RFU of the internalized yeast after an infection time of $1 \mathrm{~h}$. Data shown are based on mean and SD of three independent experiments. (b) Phagosome maturation determined by fluorescence microscopic determination of acidic phagosomes after $1.5 \mathrm{~h}$ co-cultivation. Data represent the percentage of acid phagosomes with respect to the total number counted (at least 200 phagosomes per yeast strain), and are the results of three experiments performed on different days (error bars, SD). 
between Chk1p and the response regulator CaSsklp in the investigated processes cannot be assumed.

\section{DISCUSSION}

Since the C. albicans histidine kinases Chk1p, Coslp and CaSln $1 p$ were identified as virulence factors in 1999 (Calera et al., 1999; Yamada-Okabe et al., 1999), several studies have been performed to elucidate how these enzymes contribute to the pathogenicity of this opportunistic fungus. In the last decade, it has been found that the histidine kinases are involved in a wide variety of processes, such as the conversion from yeast to hyphal forms, and the adaptation to osmotic and oxidative stress conditions (Kruppa \& Calderone, 2006). However, all three histidine kinases are also known to be associated with the regulation of cell wall mannan biosynthesis (Kruppa et al., 2003, 2004). As the fungal cell wall not only serves as a protective barrier but also is the site of interaction with host cells such as phagocytes, we were interested in whether the histidine kinases influence phagocyte responses to C. albicans infection. We found that disruption of COS1 and CaSLN1 affects phagocytosis only slightly, whereas deletion of CHK1 dramatically enhances uptake of C. albicans by different types of phagocytes. These findings are consistent with an earlier study which revealed that a CHK1-deficient C. albicans strain is totally avirulent in a mouse systemic candidiasis model, whereas during infection with $\Delta \cos 1$ and $\Delta$ cas $\ln 1$ mutants, virulence is merely reduced (Yamada-Okabe et al., 1999). It should be noted that no morphological differences between the mutants and the reference strain were observed. All strains were in the yeast form during phagocytosis assays. Hyphae formed only during prolonged co-cultivation with phagocytes. Thus, we were able to discover a novel process in which Chk1p is involved, underlining the fact that among all $C$. albicans histidine kinases, Chklp plays a prominent part in pathogenicity. Moreover, further investigations were able to show that Chklp not only is involved in the escape of $C$. albicans from being ingested by immune cells but also participates in blocking phagosome maturation, a property which has so far been exclusively described for bacterial histidine kinases (Kumagai et al., 2006). This result could provide an additional approach to explain why CHK1deficient $C$. albicans mutants have been shown to be highly susceptible to intracellular killing mechanisms of human neutrophils (Torosantucci et al., 2002). Until recently, this fact was mainly traced back to the enhanced sensitivity of the mutant to the oxidative burst.

Our next goal was to elucidate whether the role of $C$. albicans Chk1p in host-pathogen interactions is connected to its involvement in cell wall biosynthesis. The fungal cell wall is organized in a layered 3D structure consisting of polysaccharides such as chitin, mannans and $\beta$-glucans partly associated with cell wall proteins. Intensive research has been focused on the impact of the different cell wall components on immune recognition of C. albicans (for an excellent review, see Netea et al., 2008). Although all constituents of cell wall structures have been found to have the capability to stimulate immune response mechanisms, the $\beta$-glucan layer is considered to be the major immune stimulatory component of the cell wall. Paradoxically, the $\beta$-glucans of $C$. albicans have been described as buried underneath a dense mannan coat, and thus to be hidden from immune recognition (Ruiz-Herrera et al., 2006; Wheeler \& Fink, 2006). For example, analysis of sera from rabbits immunized with C. albicans has revealed predominantly anti-phosphopeptidomannan antibodies and only low levels of anti-glucan antibodies, supporting the conclusion that $\beta$-glucans are localized mainly in the inner part of the cell wall (Kondori et al., 2003). As it had already been reported that deletion of CHK1 leads to truncated mannan chains (Kruppa et al., 2003), our aim was to prove the hypothesis that the $\beta$-glucans of the mutant were exposed due to the shorter mannans. Indeed, we were able to correlate the increased efficiency of phagocyte responses to $\Delta c h k 1$ with an enhanced accessibility of the mutant surface $\beta$-1,3-glucans for immune recognition.

The receptor dectin-1 is widely described as the major $\beta$ glucan recognition receptor in innate immune defence against fungal infections. Its activation stimulates phagocytosis (Netea et al., 2008), which correlates with the increased phagocytosis activity of those strains with an increased $\beta$-1,3-glucan exposure. However, dectin-1 is also involved in cytokine secretion. Frequently IL- 6 and IL-10 are considered as indicators of dectin- 1 activation, as it has been shown that the interaction of HK C. albicans and primary human phagocytes leads to IL-6 and IL-10 secretion, which can be suppressed by blocking dectin-1 (Gow et al., 2007). However, the necessity of TLR2 in particular for IL-10 production has also been discussed (Netea et al., 2008; Goodridge et al., 2007; Slack et al., 2007), and may be dependent on the cell type (Steele et al., 2003), as in some studies a TLR2 involvement has been claimed (Netea et al., 2008), whereas others clearly show an independence from TLR2 for macrophages (Goodridge et al., 2007; Steele et al., 2003). We found an enhanced production of IL- 6 and IL-10 when macrophages were incubated with $\Delta c h k 1$ (in comparison with CAF2-1), which we took as another indicator of stronger dectin-1 involvement in the case of $\Delta \operatorname{chk} 1$.

Thus, we observed that the cytokine secretion and the efficiency of phagocytosis of all yeast strains tested in this study were directly related to the $\beta-1,3$-glucan exposure on the yeast surface. These findings correlate with those of a recently published work, in which it was discovered that treatment of C. albicans with subinhibitory concentrations of the antifungal agent caspofungin, an echinocandin targeting the $\beta$-1,3-glucan synthase, stimulates immune defence mechanisms as a consequence of an increased surface $\beta$-1,3-glucan expression (Wheeler \& Fink, 2006). Using an $S$. cerevisiae mutant libary, those authors uncovered a genetic network required for an enhanced $\beta$ glucan surface expression. The identified genes were largely 
known to be involved in polarized cell wall remodelling and cell wall integrity pathways. In contrast to that study, in our investigations the parental strain of the mutant collection also showed a significant $\beta$-glucan accessibility. The reason for this discrepancy cannot be elucidated. However, we can now identify the C. albicans histidine kinase Chk1p as a regulatory protein which influences the accessibility of the $\beta$-1,3-glucan layer for host-pathogen interactions, and which is absent in S. cerevisiae. Thus, results from the non-pathogenic yeast $S$. cerevisiae elucidate the mechanisms in C. albicans only to a limited extent, and Chklp could be considered a valuable drug target in $C$. albicans. Nevertheless, we expect that deletion not only of CHK1 but also of other genes will lead to increased $\beta$ glucan exposure, as has already been described for the MAP kinase CEK1 (Galán-Diez et al., 2010), i.e. a genetic network also exists in C. albicans that is involved in the set-up of the 3D cell wall structure and of which Chklp is one element and Cek1p another.

Further investigations are required to define in detail the intracellular mechanisms triggered by Chk1p. Fungal histidine kinases are commonly assumed to participate in two-component signal transduction systems, but until now a response regulator involved in Chklp-dependent pathways has not been identified. In our work, we could show that signalling from Chklp is unlikely to be mediated through the response regulator CaSsklp, at least in processes related to phagocytosis and phagosome acidification. This finding accords with an earlier study of a human oesophageal epithelial candidiasis model which indicated an involvement of Chk1p and CaSsklp in different transduction pathways (Li et al., 2002). As Chklp is a typical fungal hybrid histidine kinase, the protein possesses not only the histidine kinase domain but also a receiver domain (Santos \& Shiozaki, 2001). It is described as a cytosolic protein, and thus could act as a response regulator itself, as has already been discussed (Kruppa \& Calderone, 2006). Furthermore, Chk1p also contains an additional domain which shares homology with prokaryotic serine-threonine kinase domains (Calera \& Calderone, 1999a; Santos \& Shiozaki, 2001), so that a role for Chklp in MAP kinase signalling cascades has already been speculated (Kruppa \& Calderone, 2006). The C. albicans MAP kinases Mkclp and Ceklp are involved in cell wall integrity pathways and regulate cell wall biosynthesis (Monge et al., 2006). Interestingly, it has recently been shown that deletion of CEK1 also leads to truncated mannan layers (Li et al., 2009). These findings raise the question of whether the histidine kinase Chklp engages with MAP kinase pathways. Thus, future work could include $C$. albicans strains with specific point mutations to inactivate the respective protein domains of Chklp and identify those which are responsible for the effects observed in this study. Moreover, fusion proteins with fluorescent proteins would indicate whether the intracellular localization (cytosol/nucleus) of the protein changes in response to the organism's environment.
In conclusion, we have shown for the first time that the $C$. albicans histidine kinase Chk1p influences processes which enable this pathogenic fungus to mask its $\beta$-1,3-glucans from phagocyte recognition. This opens novel strategies for antifungal therapies, as the manipulation of the $3 \mathrm{D}$ structure of the cell wall by targeting the exposure of $\beta$ glucans via Chk1p does not lead to lethality, and hence does not select resistant strains, but improves the efficiency of immune defence reactions. Since homologues of fungal histidine kinases are unknown in mammals, compounds targeting these enzymes might cause fewer side effects than currently used antimycotic agents such as the polyene amphotericin B.

\section{ACKNOWLEDGEMENTS}

We gratefully thank Matthias Gunzer (present address: Otto-vonGuericke University Magdeburg, Germany) and Priyanka Narang (present address: University of York, UK) for the provision of primary murine PMNs and for continuous interest and helpful discussions. We thankfully acknowledge the provision of the C. albicans null mutant $\Delta \cos 1$ by Claude Selitrennikoff (University of Colorado Denver, USA). We are grateful to Florenz Sasse and Randi Diestel (Helmholtz Centre for Infection Research, Braunschweig, Germany) for continuous help with fluorescence microscopy. We thank our laboratory colleagues for donating blood and preparation of PMNs. N. K. acknowledges financial support by the PRO INNO programme of the Arbeitsgemeinschaft industrieller Forschungsvereinigungen (AiF), Germany. Author contributions: N. K. and U.B. conceived and designed experiments; N. K. and S.C. performed experiments; N. K. and L. G. analysed data; N. K. and U.B. wrote the paper. Competing interests: the authors have declared that no competing interests exist.

\section{REFERENCES}

Adams, E. L., Rice, P. J., Graves, B., Ensley, H. E., Yu, H., Brown, G. D., Gordon, S., Monteiro, M. A., Papp-Szabo, E. \& other authors (2008). Differential high-affinity interaction of dectin-1 with natural or synthetic glucans is dependent upon primary structure and is influenced by polymer chain length and side-chain branching. J Pharmacol Exp Ther 325, 115-123.

Alex, L. A., Korch, C., Selitrennikoff, C. P. \& Simon, M. I. (1998). COS1, a two-component histidine kinase that is involved in hyphal development in the opportunistic pathogen Candida albicans. Proc Natl Acad Sci U S A 95, 7069-7073.

Bahn, Y. S. (2008). Master and commander in fungal pathogens: the two-component system and the HOG signaling pathway. Eukaryot Cell 7, 2017-2036.

Bahn, Y. S., Xue, C., Idnurm, A., Rutherford, J. C., Heitman, J. \& Cardenas, M. E. (2007). Sensing the environment: lessons from fungi. Nat Rev Microbiol 5, 57-69.

Behnsen, J., Narang, P., Hasenberg, M., Gunzer, F., Bilitewski, U., Klippel, N., Rohde, M., Brock, M., Brakhage, A. A. \& other authors (2007). Environmental dimensionality controls the interaction of phagocytes with the pathogenic fungi Aspergillus fumigatus and Candida albicans. PLoS Pathog 3, e13.

Brachmann, C. B., Davies, A., Cost, G. J., Caputo, E., Li, J., Hieter, P. \& Boeke, J. D. (1998). Designer deletion strains derived from Saccharomyces cerevisiae S288C: a useful set of strains and plasmids for PCR-mediated gene disruption and other applications. Yeast 14, $115-132$. 
Brown, G. D., Taylor, P. R., Reid, D. M., Willment, J. A., Williams, D. L., Martinez-Pomares, L., Wong, S. Y. \& Gordon, S. (2002). Dectin-1 is a major $\beta$-glucan receptor on macrophages. J Exp Med 196, 407-412.

Calderone, R. A. \& Fonzi, W. A. (2001). Virulence factors of Candida albicans. Trends Microbiol 9, 327-335.

Calera, J. A. \& Calderone, R. (1999a). Flocculation of hyphae is associated with a deletion in the putative CaHK1 two-component histidine kinase gene from Candida albicans. Microbiology 145, 14311442 .

Calera, J. A. \& Calderone, R. A. (1999b). Identification of a putative response regulator two-component phosphorelay gene (CaSSK1) from Candida albicans. Yeast 15, 1243-1254.

Calera, J. A., Choi, G. H. \& Calderone, R. A. (1998). Identification of a putative histidine kinase two-component phosphorelay gene (CaHK1) in Candida albicans. Yeast 14, 665-674.

Calera, J. A., Zhao, X. J., De Bernardis, F., Sheridan, M. \& Calderone, R. (1999). Avirulence of Candida albicans CaHK1 mutants in a murine model of hematogenously disseminated candidiasis. Infect Immun 67, 4280-4284.

Calera, J. A., Zhao, X. J. \& Calderone, R. (2000). Defective hyphal development and avirulence caused by a deletion of the SSK1 response regulator gene in Candida albicans. Infect Immun 68, 518525.

Chaffin, W. L., Lopez-Ribot, J. L., Casanova, M., Gozalbo, D. \& Martinez, J. P. (1998). Cell wall and secreted proteins of Candida albicans: identification, function, and expression. Microbiol Mol Biol Rev 62, 130-180.

Chauhan, N. \& Calderone, R. (2008). Two-component signal transduction proteins as potential drug targets in medically important fungi. Infect Immun 76, 4795-4803.

Chauhan, N., Inglis, D., Roman, E., Pla, J., Li, D., Calera, J. A. \& Calderone, R. (2003). Candida albicans response regulator gene SSK1 regulates a subset of genes whose functions are associated with cell wall biosynthesis and adaptation to oxidative stress. Eukaryot Cell 2, 1018-1024.

Cowen, L. E. \& Steinbach, W. J. (2008). Stress, drugs, and evolution: the role of cellular signaling in fungal drug resistance. Eukaryot Cell 7 , 747-764.

Fernández-Arenas, E., Bleck, C. K., Nombela, C., Gil, C., Griffiths, G. \& Diez-Orejas, R. (2009). Candida albicans actively modulates intracellular membrane trafficking in mouse macrophage phagosomes. Cell Microbiol 11, 560-589.

Fonzi, W. A. \& Irwin, M. Y. (1993). Isogenic strain construction and gene mapping in Candida albicans. Genetics 134, 717-728.

Galán-Diez, M., Arana, D. M., Serrano-Gomez, D., Kremer, L., Casasnovas, J. M., Ortega, M., Cuesta-Dominguez, A., Corbi, A. L., Pla, J. \& other authors (2010). Candida albicans $\beta$-glucan exposure is controlled by the fungal CEK1-mediated mitogen-activated protein kinase pathway that modulates immune responses triggered through dectin-1. Infect Immun 78, 1426-1436.

Gantner, B. N., Simmons, R. M. \& Underhill, D. M. (2005). Dectin-1 mediates macrophage recognition of Candida albicans yeast but not filaments. $E M B O$ J 24, 1277-1286.

Goodridge, H. S., Simmons, R. M. \& Underhill, D. M. (2007). Dectin-1 stimulation by Candida albicans yeast or zymosan triggers NFAT activation in macrophages and dendritic cells. J Immunol 178, 31073115

Gow, N. A., Netea, M. G., Munro, C. A., Ferwerda, G., Bates, S., MoraMontes, H. M., Walker, L., Jansen, T., Jacobs, L. \& other authors (2007). Immune recognition of Candida albicans $\beta$-glucan by dectin1. J Infect Dis 196, 1565-1571.
Herre, J., Marshall, A. S., Caron, E., Edwards, A. D., Williams, D. L., Schweighoffer, E., Tybulewicz, V., Reis e Sousa, C., Gordon, S. \& other authors (2004). Dectin-1 uses novel mechanisms for yeast phagocytosis in macrophages. Blood 104, 4038-4045.

Ibata-Ombetta, S., Jouault, T., Trinel, P. A. \& Poulain, D. (2001). Role of extracellular signal-regulated protein kinase cascade in macrophage killing of Candida albicans. J Leukoc Biol 70, 149-154.

Janusz, M. J., Austen, K. F. \& Czop, J. K. (1988). Phagocytosis of heatkilled blastospores of Candida albicans by human monocyte betaglucan receptors. Immunology 65, 181-185.

Jouault, T., El Abed-El Behi, M., Martinez-Esparza, M., Breuilh, L., Trinel, P. A., Chamaillard, M., Trottein, F. \& Poulain, D. (2006). Specific recognition of Candida albicans by macrophages requires galectin-3 to discriminate Saccharomyces cerevisiae and needs association with TLR2 for signaling. J Immunol 177, 4679-4687.

Klippel, N. \& Bilitewski, U. (2007). Phagocytosis assay based on living Candida albicans for the detection of effects of chemicals on macrophages function. Anal Lett 40, 1400-1411.

Kondori, N., Edebo, L. \& Mattsby-Baltzer, I. (2003). Candida albicans cell wall antigens for serological diagnosis of candidemia. Med Mycol 41, 21-30.

Kruppa, M. \& Calderone, R. (2006). Two-component signal transduction in human fungal pathogens. FEMS Yeast Res 6, 149159.

Kruppa, M., Goins, T., Cutler, J. E., Lowman, D., Williams, D., Chauhan, N., Menon, V., Singh, P., Li, D. \& other authors (2003). The role of the Candida albicans histidine kinase (CHK1) gene in the regulation of cell wall mannan and glucan biosynthesis. FEMS Yeast Res 3, 289-299.

Kruppa, M., Jabra-Rizk, M. A., Meiller, T. F. \& Calderone, R. (2004). The histidine kinases of Candida albicans: regulation of cell wall mannan biosynthesis. FEMS Yeast Res 4, 409-416.

Kumagai, Y., Cheng, Z., Lin, M. \& Rikihisa, Y. (2006). Biochemical activities of three pairs of Ehrlichia chaffeensis two-component regulatory system proteins involved in inhibition of lysosomal fusion. Infect Immun 74, 5014-5022.

Le Cabec, V., Emorine, L. J., Toesca, I., Cougoule, C. \& Maridonneau-Parini, I. (2005). The human macrophage mannose receptor is not a professional phagocytic receptor. J Leukoc Biol 77, 934-943.

Lee, S. J., Zheng, N. Y., Clavijo, M. \& Nussenzweig, M. C. (2003). Normal host defense during systemic candidiasis in mannose receptor-deficient mice. Infect Immun 71, 437-445.

Li, D., Bernhardt, J. \& Calderone, R. (2002). Temporal expression of the Candida albicans genes CHK1 and CSSK1, adherence, and morphogenesis in a model of reconstituted human esophageal epithelial candidiasis. Infect Immun 70, 1558-1565.

Li, D., Williams, D., Lowman, D., Monteiro, M. A., Tan, X., Kruppa, M., Fonzi, W., Roman, E., Pla, J. \& other authors (2009). The Candida albicans histidine kinase Chk1p: signaling and cell wall mannan. Fungal Genet Biol 46, 731-741.

Martínez-Esparza, M., Sarazin, A., Jouy, N., Poulain, D. \& Jouault, T. (2006). Comparative analysis of cell wall surface glycan expression in Candida albicans and Saccharomyces cerevisiae yeasts by flow cytometry. J Immunol Methods 314, 90-102.

Meyer-Wentrup, F., Figdor, C. G., Ansems, M., Brossart, P., Wright, M. D., Adema, G. J. \& van Spriel, A. B. (2007). Dectin-1 interaction with tetraspanin CD37 inhibits IL-6 production. J Immunol 178, 154162.

Mitchell, A. P. (1998). Dimorphism and virulence in Candida albicans. Curr Opin Microbiol 1, 687-692. 
Monge, R. A., Roman, E., Nombela, C. \& Pla, J. (2006). The MAP kinase signal transduction network in Candida albicans. Microbiology 152, 905-912.

Moran, C., Grussemeyer, C. A., Spalding, J. R., Benjamin, D. K., Jr \& Reed, S. D. (2009). Candida albicans and non-albicans bloodstream infections in adult and pediatric patients: comparison of mortality and costs. Pediatr Infect Dis J 28, 433-435.

Nagahashi, S., Mio, T., Ono, N., Yamada-Okabe, T., Arisawa, M., Bussey, H. \& Yamada-Okabe, H. (1998). Isolation of CaSLN1 and $C a N I K 1$, the genes for osmosensing histidine kinase homologues, from the pathogenic fungus Candida albicans. Microbiology 144, 425432 .

Netea, M. G., Brown, G. D., Kullberg, B. J. \& Gow, N. A. (2008). An integrated model of the recognition of Candida albicans by the innate immune system. Nat Rev Microbiol 6, 67-78.

Poulain, D. \& Jouault, T. (2004). Candida albicans cell wall glycans, host receptors and responses: elements for a decisive crosstalk. Curr Opin Microbiol 7, 342-349.

Ruiz-Herrera, J., Elorza, M. V., Valentin, E. \& Sentandreu, R. (2006). Molecular organization of the cell wall of Candida albicans and its relation to pathogenicity. FEMS Yeast Res 6, 14-29.

Santos, J. L. \& Shiozaki, K. (2001). Fungal histidine kinases. Sci STKE 2001, rel.

Singh, P., Chauhan, N., Ghosh, A., Dixon, F. \& Calderone, R. (2004). SKN7 of Candida albicans: mutant construction and phenotype analysis. Infect Immun 72, 2390-2394.

Singh, S. D., Robbins, N., Zaas, A. K., Schell, W. A., Perfect, J. R. \& Cowen, L. E. (2009). Hsp90 governs echinocandin resistance in the pathogenic yeast Candida albicans via calcineurin. PLoS Pathog 5, e1000532.

Siqueira, J. F., Jr \& Sen, B. H. (2004). Fungi in endodontic infections. Oral Surg Oral Med Oral Pathol Oral Radiol Endod 97, 632-641.

Slack, E. C., Robinson, M. J., Hernanz-Falcon, P., Brown, G. D., Williams, D. L., Schweighoffer, E., Tybulewicz, V. L. \& Reis e Sousa, C. (2007). Syk-dependent ERK activation regulates IL-2 and IL-10 production by DC stimulated with zymosan. Eur J Immunol 37, 16001612.
Steele, C., Marrero, L., Swain, S., Harmsen, A. G., Zheng, M., Brown, G. D., Gordon, S., Shellito, J. E. \& Kolls, J. K. (2003). Alveolar macrophage-mediated killing of Pneumocystis carinii f. sp. muris involves molecular recognition by the dectin-1 $\beta$-glucan receptor. J Exp Med 198, 1677-1688.

Stehr, F., Felk, A., Kretschmar, M., Schaller, M., Schafer, W. \& Hube, B. (2000). Extracellular hydrolytic enzymes and their relevance during Candida albicans infections. Mycoses 43 (Suppl. 2), 17-21.

Taylor, P. R., Brown, G. D., Reid, D. M., Willment, J. A., MartinezPomares, L., Gordon, S. \& Wong, S. Y. (2002). The $\beta$-glucan receptor, dectin-1, is predominantly expressed on the surface of cells of the monocyte/macrophage and neutrophil lineages. J Immunol 169, 3876-3882.

Taylor, P. R., Tsoni, S. V., Willment, J. A., Dennehy, K. M., Rosas, M., Findon, H., Haynes, K., Steele, C., Botto, M. \& other authors (2007). Dectin- 1 is required for $\beta$-glucan recognition and control of fungal infection. Nat Immunol 8, 31-38.

Tkacz, J. S., Cybulska, E. B. \& Lampen, J. O. (1971). Specific staining of wall mannan in yeast cells with fluorescein-conjugated concanavalin A. J Bacteriol 105, 1-5.

Torosantucci, A., Chiani, P., De Bernardis, F., Cassone, A., Calera, J. A. \& Calderone, R. (2002). Deletion of the two-component histidine kinase gene (CHK1) of Candida albicans contributes to enhanced growth inhibition and killing by human neutrophils in vitro. Infect Immun 70, 985-987.

Wheeler, R. T. \& Fink, G. R. (2006). A drug-sensitive genetic network masks fungi from the immune system. PLoS Pathog 2, e35.

Wheeler, R. T., Kombe, D., Agarwala, S. D. \& Fink, G. R. (2008). Dynamic, morphotype-specific Candida albicans $\beta$-glucan exposure during infection and drug treatment. PLoS Pathog 4, e1000227.

Willment, J. A. \& Brown, G. D. (2008). C-type lectin receptors in antifungal immunity. Trends Microbiol 16, 27-32.

Yamada-Okabe, T., Mio, T., Ono, N., Kashima, Y., Matsui, M., Arisawa, M. \& Yamada-Okabe, H. (1999). Roles of three histidine kinase genes in hyphal development and virulence of the pathogenic fungus Candida albicans. J Bacteriol 181, 7243-7247.

Edited by: J. Pla 